\title{
Recurrence Rates and Mesh Shrinkage After Polypropylene vs. Polyester Mesh Hernia Repair in Complicated Hernias
}

\begin{abstract}
BOGDAN SOCEA1, LAURA ILEANA SOCEA2*, OVIDIU GABRIEL BRATU³, BOGDAN MASTALIER ${ }^{4}$, MIHAI DIMITRIU1, ALEXANDRU CARAP1 ${ }^{1}$ VLAD DENIS CONSTANTIN ${ }^{1}$

'University of Medicine and Pharmacy Carol Davila, Faculty of General Medicine, St. Pantelimon Emergency Hospital, 340-342 Soseaua Pantelimon, 021659, Bucharest, Romania

2University of Medicine and Pharmacy Carol Davila, Faculty of Pharmacy, 6 Traian Vuia Str., 020956, Bucharest, Romania 3University of Medicine and Pharmacy Carol Davila, Faculty of General Medicine, Emergency Universitary Central Military Hospital, 134 Calea Plevnei, 010825, Bucharest, Romania

"University of Medicine and Pharmacy Carol Davila, Faculty of General Medicine, Colentina Clinical Hospital, 19-21 Stefan cel Mare Blvd., 020125, Bucharest, Romania

Prosthetic mesh implants in hernia repair are frequently used based on the fact that lower recurrence rates are detected compared to anatomic repair. In latest years, researchers tried to answer weather there is an ideal mesh material for abdominal hernia repair. The studies tried to compare resistance, bio-tolerance, rates of recurrence and infection of several materials used in alloplasty. The results are far from pointing an unique ideal chemical structure of mesh. In our study, we compared the results of a cohort of 265 patients operated in 2010 and 2011 in our clinic for complicated abdominal incisional hernias. We compared the results of polypropylene mesh vs. polyester. Polypropylene mesh proved significantly better for preventing hernia recurrence and showed a lower shrinkage rate.
\end{abstract}

Keywords: Polypropylene mesh, polyester mesh, recurrence rate, abdominal hernia, mesh shrinkage

The concept of using a mesh to repair a hernia was introduced about 60 years ago. In 1958 Usher published his technique that involved a polypropylene mesh.

There are lots of scientific debates about an ideal material for mesh parietal repair. In latest years, the tendency is that the continuous decreasing territory of polyester mesh to be slowly replaced by the increasing territory of polypropylene mesh in open procedures for abdominal incisional hernia repair. We did this study in 2010 - 2011, at that time, in our Clinic, the use of polyester polyethylene terephthalate (PET) Vs. polypropylene (PP) meshes were slightly equal (fig. 1).

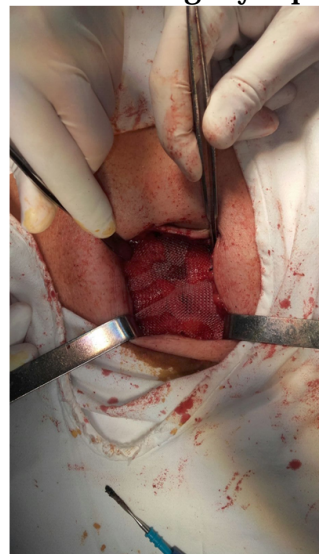

Fig. 1. Intraoperative findings for onlay technique

Uncoated, lightweight, macroporous, monofilament polyester mesh has been shown to demonstrate improved bacterial clearance, better tissue integration, reduced foreign body response, and less chronic pain for hernia repair [1]. Polyester meshes appear to give high incidence of mechanical failures, in the context of open incisional hernia repair, due to the weakness of all lightweight meshes and surgeons should be aware that these failures have already been documented [1].

In cases of hernia mesh repair, mesh-induced chronic inflammatory response in the patient's own tissue may lead to postoperative complications. The response depends both on the chemical composition and the filament structure. It is elevated to multifilament mesh structure versus monofilament one, and seem to be increased in polyester structures vs. polypropylene [2].

The quality of mesh integration also depends on the dimension of mesh structure pores, the larger they are, the significantly better tissue integration was showed, independent of the mesh weight [3]. The shrinkage in time is an important predictor of hernia recurrence. So, it is ideal to obtain a minimum or no shrinkage. The minimum shrinkage was measured for heavyweight large pore meshes [4]. Lightweight meshes with large pore size and lack of structural stability leads to mesh shrinkage [4].

The mesh weight is expressed in $\mathrm{g} / \mathrm{sgm}$. Low weight is notalways synonymous with large pores. There are modern heavyweight large pore meshes which seem the best choice for hernia repair. We can use rigid meshes with large pores in large defects. Lightweight meshes are exposed to migration in cases of large defect and this is a cause of recurrence. Large pores permit best fibrin bands development in the tissue. In cases of small pores, the fibrin bands confluence in a rigid structure.

Recent studies showed that the chemical structure of polymeric mesh is altered by the oxidative stress in biological tissues. It was shown that structural changes in polypropylene meshes exposed to oxidative stress may involve formation of cross-links between the polymer chains, chain scissions, and hydrogen bonds between the carboxyl groups, which are formed in the material during the oxidation [5]. All these alteration could be responsible for mesh stiffening.

Some condensation polymers, like polyesters, are susceptible to hydrolysis, given their molecular structure. Polymer composites do not dissolve in water but they are able to absorb water in different quantities depending on their composition [6].

*email: laurasocea@gmail.com 


\section{Experimental part}

Materials and methods

265 Patients were admitted and operated on, in Surgery Ward of St. Pantelimon Emergency Hospital Bucharest during the period $1^{\text {st }}$ of January 2010 - 31 $1^{\text {st }}$ of December 2011 for complicated abdominal incisional hernias. The design of the study is both retrospective and prospective. We retrospectively collect data of these patients and then we started a follow-up period of five years for each patient (between 2011 and 2016). We collected from the primary operation demographic data, the diagnostic at the operation time (type of complication), the surgical procedure done, the type and the dimensions of mesh used. We counted readmissions for these patients and reinterventions for recurrent incisional hernia. During reintervention, we measured the mesh to calculate mesh shrinkage compared with initial dimension.

The patients included in study were presented at the emergency ward with irreducible incisional hernia, either incarcerated, or strangulated hernia. We excluded the cases of strangulation with bowel necrosis and peritonitis, in which the use of synthetic mesh was prohibited and done only in few specific cases, under specific precautions and using another kind of meshes (biological, resorbable meshes). The use of biomaterials, such as collagen or collagen coated meshes seem to be a better option for potentially infected sites. There are new papers that study the adhesion capacities of collagen matrix for mesenchymal cells [7].

Consented patients aged over 18 years scheduled for open incisional hernia repair were eligible. General anesthesia was administrated, at which time patients were administrated intravenous single prophylactic antibiotics dose, according to our practice and recommendations. After identification, opening and dissection of the hernia sac, the abdominal wall defect was measured to assure an adequate mesh overlap. We used in all cases a mesh dimensioned and placed in such way that it outdistanced the margins of the defect with minimum 5 centimeters in all directions. The meshes were placed retro-muscular (under abdominal rectus muscles), with separate closure of posterior and anterior fascia, in several cases or onlay in most cases (both for polypropylene and polyester) (fig. 2).

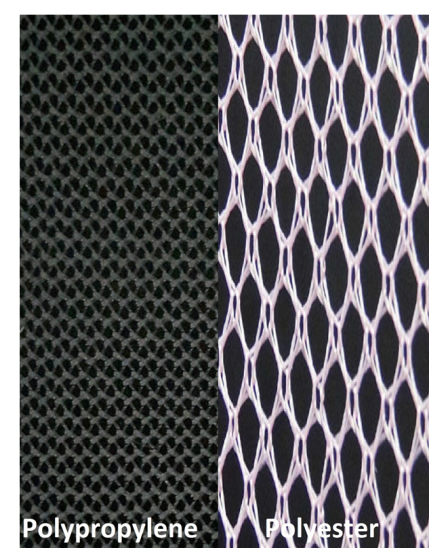

Fig. 2. Polypropylene vs. polyester mesh structure for hernia repair

In 148 cases we used a polypropylene mesh and in 117 a polyester mesh.

The technique was retro-muscular for 57 cases of polypropylene use and, respectively, 31 of those with polyester mesh alloplasty.

Clinical assessments were done at all patients at discharge and at 1, 3, 6, 12, 24 months and 5 years followup period, or whenever itwas required (unscheduled time) by complications or recurrence.

\section{Results and discussions}

The surgical teams were homogenous regarding experience, surgical decisions and operating procedures for both groups (the 148 patients repaired with polypropylene mesh (PP) vs. those 117 patients on which we used polyester (PET) mesh).

From the total of abdominal defects operated on in our clinic in 2010 and $2011,45 \%$ presented with uncomplicated incisional hernia and $4 \%$ with strangulated hernia and peritonitis (bowel necrosis), which were excluded. This study referred to the rest of $51 \%$ (265 patients), with emergency presentations for complicated incisional hernias without necrosis (incarcerated and strangulated, but not gangrenous). All the patients in this study underwent open hernia repair.

Sex ratio (M:F) was 0.436 for $P P$ and 0.55 for $P E$. Mean age was 52.2 years for PP group and, respectively, 59.5 year for PE group. The age distribution show ed a similarity between the two groups (fig. 3).

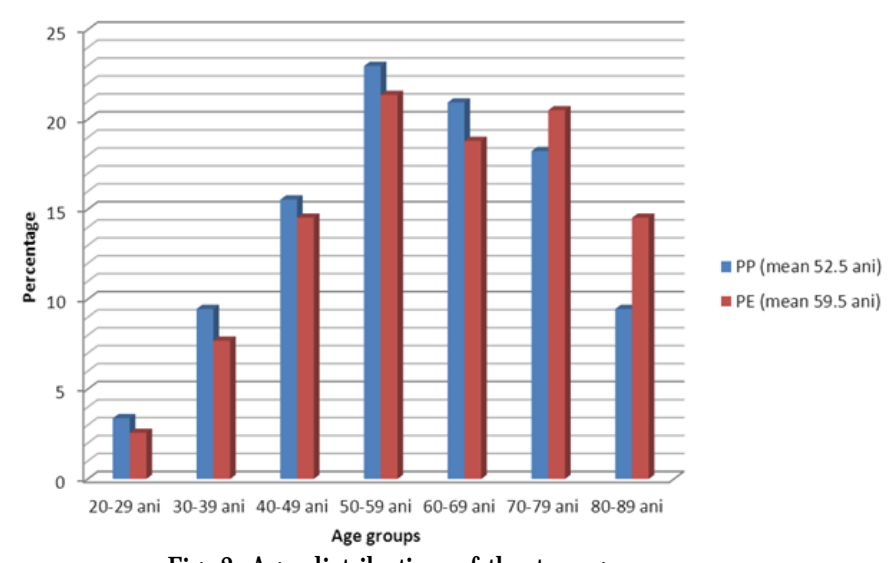

Fig. 3. Age distribution of the two groupsroups

The overall mean Body Mass Index was $28.8 \mathrm{~kg} / \mathrm{mp}$ $(29.1 \mathrm{~kg} / \mathrm{mp}$ for $\mathrm{PP}$, and $28.4 \mathrm{~kg} / \mathrm{mp}$ for $\mathrm{PE}$ ).

There was an overall recurrence rate of $8.3 \%$ (22 patients), who underwent reoperations in the five years follow-up period (2011-2015 for the patients primarily operated in 2010, respectively 2012-2016 for those first operated in 2011). The limits of these study was the lack of compliance for presenting at follow-up visits (occurred at 17 patients $-6.41 \%$ ), and, on the other way, the patients that could be reoperated in other clinics. The overall recurrence rate is comparable with those found in literature. In a very recent meta-analysis of studies from multiple countries, after two years from open mesh repair for incisional abdominal hernia, 8 to $12 \%$ of patients had developed a recurrence [8], consequently, we are far from the position to speak of surgical cure by mesh. However, recurrence rates after open repair tend to be lower compared to those after laparoscopic surgery [9].

The recurrence appeared in 16 cases with polyester abdominal repair (13.67\%), compared to only 6 cases of PP $(4.05 \%)$. The difference is statistically lower for polypropylene mesh (fig. 4).

The overall mean time interval for recurrence was 16.3 months, with no differences between PP and PE, results concordant to those in the literature. Our follow-up period was of 60 months, but all the recurrences were noted in the first 24 months after primary repair. Thus, we conclude that a 2 years follow-up period is sufficient to detect the recurrences. In the literature, most studies have a 2-years follow-up period, anyway [10].

For the 22 patients that underwent reoperations, during the second procedure, we measure the area covered by the mesh (the mesh dimensions). We could compare these 
Recurrence rate (\%)

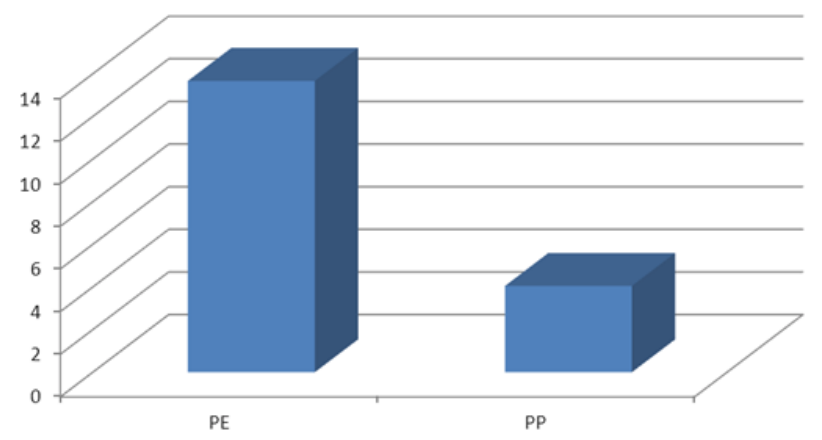

Fig. 4. Comparative recurrence rates for the two types of meshes

dimensions with the initial dimensions of the mesh used, mentioned in the protocol. We could thus calculate mesh shrinkage in time (mean time 16.3 months, which is the mean time of recurrence).

For PP mesh, the mean shrinkage percent was 9.8, at the mean interval of 16.7 months, while PE showed $20.3 \%$ shrinkage at 15.2 months (fig. 5). These data are also concordant with those from the literature [11].

Shrinkage occurs due to the scar tissue formed near the mesh and which tend to completely cover the mesh. The shrinkage rate is the greater the time passes [12]. We effectively measured mesh shrinkage at reintervention time and that could be a limit to estimate long-time shrinkage.

Nanofibers are certainly showing a strong potential to become a new generation of materials used notespecially alone, but for coating surgical meshes. They have some promisingly features of cellular adhesion, minimization of inflammatory tissue response and their ultra light weight (higher porosity and smaller pore size) [13].

\section{Conclusions}

Polypropylene mesh is a better solution for hernia repair than polyester. Heavyweight large pores structure seems to be best integrated in human tissues. Polypropylene mesh provides better repair (lower recurrence rate and lower mesh shrinkage rate in time). All recurrences appeared in the first two years after primary repair.
Mesh shrinkage (\%)

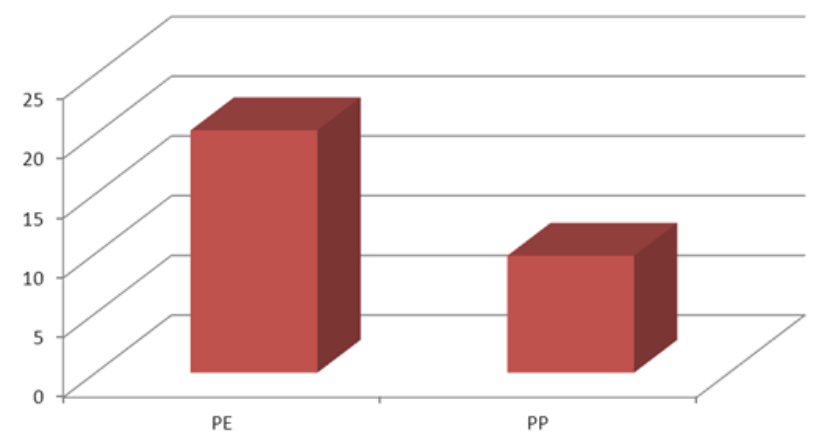

Fig. 5. Comparative mesh shrinkage at recurrence time

\section{References}

1. PETRO C. C., NAHABET E. H., CRISS C. N., ORENSTEIN S. B., VON RECUM H. A., NOVITSKY Y. W. , ROSEN M. J., Hernia, 19 no 1, 2015, p. 155

2. NGUYEN P.T., ASARIAS J.R., PIERCE L.M., J. Invest. Surg., 25 no 5, 2012, p.330

3. LAKE S. P., RAY S., ZIHNI A. M., THOMPSON D. M.J R, GLUCKSTEIN J., DEEKEN C. R., J. Mech. Behav. Biomed. Mater., 42, 2015, p.186

4. WEYHE D, COBB W, LECUIVRE J, ALVES A, LADET S, LOMANTO D, BAYON Y. Int. J. Surg., 22, 2015, p.46

5. GIL D., REX J., REUKOV V., VERTEGEL A., 2017, Oct 25. doi: 10.1002/ jbm.b.34029

6. BRYLL, K., GAWDZINSKA, K., NABIALEK, M., PAWLOWSKA.,P., Rev. Chim. (Bucharest), 68, no. 9, 2017, p. 2034

7. TATU, C.S., PANAITESCU, C., MARUSCIAC, L., SISU, A.M., CRISTEA, M., PUSCASIU, D.A., TANASIE, G., Rev. Chim. (Bucharest), 68 no. 9, 2017, p. 2079

8. DIETZ U.A., MENZEL S., LOCK J., WIEGERING A., Dtsch. Arztebl. Int., 115 no3, 2018, p. 31

9. ITANI K.M., HUR K., KIM L.T., ANTHONY T., BERGER D.H., REDA D., NEUMAYER L., Arch. Surg., 145, 2010, p. 322

10 SANCHEZ L. J., PICCOLI M., FERRARI C. G., COCOZZA E., CESARI M., MAIDA P., IUPPA A., PAVONE G., BENCINI L., Int. J. Surg., 51, 2018, p. 31

11. ZOGBI L., TRINDADE E. N., TRINDADE M. R., Hernia., 17 no 6, 2013, p. 765

12. BROWN C.N., FINCH J.G., Ann. R. Coll. Surg. Engl., 92 no 4, 2010, p. 272

13. BAYLON K., RODRIGUEZ-CAMARILLO P., ELIAS-ZUNIGA A., DIAZELIZONDO J.A., GILKERSON R., LOZANO K., Membranes, 7 no 3, 2017, p. 47

Manuscript received: 27.09. 2017 